\title{
Diferenciais compensatórios de salário e o pagamento do adicional de insalubridade por ruído no Brasil ${ }^{1}$
}

\author{
Paulo Henrique Adib Dantas Salim ${ }^{2}$ \\ Marco Antonio Jorge ${ }^{3}$
}

\begin{abstract}
Resumo: No Brasil, a exposição ao ruído acima do limite legal prevê um adicional de $20 \%$ sobre o salário mínimo. Este artigo objetiva propor uma alternativa de pagamento do adicional de insalubridade para o ruído e está organizado em três seções, além da introdução. Na primeira, apresenta-se o referencial teórico baseado na teoria dos diferenciais compensatórios de salário e o marco legal referente à insalubridade e ao ruído no Brasil. A segunda seção apresenta a aplicação do modelo proposto e na última seção são apresentadas as considerações finais do trabalho, dentre elas, a de que haveria um ganho de eficiência com a sua implementação.
\end{abstract}

Palavras-chave: Diferenciais compensatórios de salário. Adicional de insalubridade. Ruído. Brasil.

Classificação JEL: J31, J33, D61.

\section{Compensatory wage differentials and insalubrity additional payment for noise in} Brazil

\begin{abstract}
In Brazil exposure to noise above the legal tolerance limit provides a $20 \%$ of the minimum wage additional. This article aims to create an alternative proposal for insalubrity additional payment for the noise, and it is organized in three sections, besides the introduction. The first one presents the theoretical framework based on the theory of compensatory wage differentials, as well as the legal treatment of unhealthiness and the noise in Brazil. The second section presents the application of the proposed model and the last section presents concluding remarks, among them, that there would be a gain in efficiency with its implementation.
\end{abstract}

Keywords: Compensatory wage differentials. Insalubrity additional. Noise. Brazil.

1 Os autores agradecem aos valiosos comentários do parecerista da Revista. Eventuais erros e incorreções remanescentes são de nossa exclusiva responsabilidade.

2 Engenheiro de Produção, Engenheiro de Segurança do Trabalho e Mestre em Economia pela Universidade Federal de Sergipe. E-mail: pauloadib.salim@gmail.com

3 Doutor em Economia de Empresas pela Fundação Getúlio Vargas/SP. Professor Associado do Departamento de Economia da Universidade Federal de Sergipe. E-mail: mjorge@ufs.br 


\section{Introdução}

Segundo Pereira (2015), uma das maiores fontes de pagamento de adicionais de insalubridade e de lesões permanentes aos trabalhadores é o ruído ocupacional. Pelas estatísticas de insalubridades e processos indenizatórios em face da Previdência Social ou por responsabilidade civil contra empregadores, o ruído ocupa, normalmente, a primeira posição (SALIM, 2002; PEREIRA, 2015). No entanto, há um grande gap entre os fundamentos clássicos da teoria econômica do trabalho e a realidade jurídica e técnica das empresas brasileiras no tocante ao pagamento à exposição de riscos ambientais, como o ruído. Com quase meia década sem grandes inovações, as normas de segurança e medicina do trabalho garantem adicionais pré-estabelecidos para os trabalhadores em certas condições. ${ }^{4}$

Nessa linha de pesquisa que relaciona diferenciais compensatórios de salário com o risco do ambiente de trabalho, foram elaborados importantes trabalhos como os de Viscusi (1984), (1986) e (1993), Viscusi e Aldy (2002), Black e Kniesner (2003) e Kniesner e Leeth (1991).

Há mais de 30 anos, Viscusi (1984) já chamava a atenção para a eficiência como um dos dois objetivos a serem perseguidos pelos programas de compensação de doenças ou riscos ocupacionais: equidade (tratar as vítimas de forma similar) e eficiência (assegurar níveis eficientes de risco). A característica inercial do risco cerca de $2 / 3$ do nível de risco é transmitido de um ano para outro no setor industrial - reforça a necessidade de programas eficientes de combate ao risco (VISCUSI, 1986). Além disso, o risco de um acidente de trabalho fatal é maior do que o risco de um acidente fatal doméstico (VISCUSI, 1993).

No Brasil, a exposição ao ruído acima do limite de tolerância prevê um adicional de $20 \%$ sobre o salário mínimo. Contudo, o problema é que se trata de uma decisão binária entre pagar $20 \%$ ou não pagar nada. Essa situação faz com que trabalhadores expostos a níveis um pouco menores do que o limite de tolerância nada recebam e aqueles expostos a níveis desumanos de ruído recebam os mesmos $20 \%$.

Embora, como será visto adiante, o limite brasileiro de tolerância seja similar ao permitido na União Europeia (http://www.osha.eu.int) e nos Estados Unidos (http://www.osha.gov) - 85 decibéis (dB) - nessas localidades não se prevê qualquer pagamento de adicional, caso o referido limite seja excedido 5 .

4 A recente reforma trabalhista aprovada pelo Congresso Nacional não alterou a seção XIII (arts. 189 a 197) da Consolidação das Leis do Trabalho (CLT), justamente a seção que trata das atividades insalubres ou perigosas.

5 A norma que disciplina a questão do ruído na União Europeia é a Diretiva 2003/10/CE, em vigor desde 2006. 0 pico de exposição permitido é de 87 dB. Nos Estados Unidos, vigora a norma OSHA 1910.95, cujo pico de exposição permitido é de $90 \mathrm{~dB}$. Ambas as normas, porém, obrigam a adequação do ambiente de trabalho e o fornecimento de protetores auditivos nos casos em que o limite de $85 \mathrm{~dB}$ é excedido (para trabalhadores em turno integral). Não há previsão de compensação monetária. 
Nesse sentido, o presente trabalho busca investigar "Qual seria a forma de pagamento justo de adicional de insalubridade por nível deruído? "e "Como a teoria econômica pode ajudar na elaboração das normas de segurança e medicina do trabalho?"

Este artigo tem como objetivo criar uma proposta alternativa de pagamento do adicional de insalubridade para o ruído, considerando as atuais referências de 10\%, 20\% e 40\% da Norma Regulamentadora no 15 do Ministério do Trabalho e Emprego para os diversos tipos de exposição. Trata-se de um modelo que adequa um nível de risco (representado pela dose de ruído) a um percentual de pagamento, gerando maior bem-estar social. Para desenvolvimento do modelo, considerou-se um intervalo de pagamento de $10 \%$ a $20 \%$ da dose de ruído, respectivamente, de 0,5 a 1,e o pagamento de $20 \%$ a $40 \%$ da dose de ruído de 1 até 5 , mantendo $40 \%$ para valores acima de dose 5 .

Assim, a contribuição do presente artigo consiste na proposição de um modelo de pagamento de adicional de insalubridade que reduza as ineficiências do mercado de trabalho, possibilitando um aumento de bem-estar de empresas e de trabalhadores, a quem a norma objetiva proteger.

Para tanto, o trabalho está organizado em três seções, além desta introdução. Na segunda seção apresenta-se uma revisão da literatura baseada na teoria dos diferenciais compensatórios de salários, além do marco legal referente ao tratamento da insalubridade e sobre ruído no Brasil. A terceira seção apresenta o modelo proposto, baseado na teoria hedonista do salário. Por fim, na quarta seção são apresentadas as considerações finais do trabalho.

Antecipadamente, pode-se apontar que o adicional fixo não resulta na maximização da utilidade, desrespeitando as preferências dos trabalhadores com relação ao nível de risco. Assim, uma das conclusões do trabalho é a de que o novo modelo, apresentado com diferencial compensatório variável em relação à dose de ruído, traria um maior nível de bem-estar.

\section{Revisão da literatura}

Esta seção tem por objetivo apresentar o referencial teórico baseado na Teoria dos Diferenciais Compensatórios de Salário, bem como o marco legal brasileiro acerca das questões de insalubridade e ruído no ambiente de trabalho.

\subsection{Diferenciais compensatórios de salários}

Um modelo é uma representação matemática e lógica de algum aspecto da economia como as escolhas do consumidor, a postura das firmas, a concorrência de mercados e até mesmo de economias completas (agregados). A existência de modelos facilita a interpretação e previsão de fenômenos através das relações de 
causa e efeito. No mercado de trabalho não é diferente:há modelos para explicar a existência de diferentes salários nas diversas situações de risco como a Teoria Hedonista dos Salários.

Para Cahuc \& Zylberberg (2004), a decisão relativa à oferta de trabalho está fundamentada na escolha do agente econômico detentor do fator de produção trabalho, o qual escolhe trabalhar, ou não, de acordo com o salário pago pelo mercado, a renda que ele é capaz de obter fora do mercado de trabalho (aluguéis ou benefícios de programas de transferência de renda, por exemplo) e suas preferências por trabalho e lazer. Considerando-se que o tempo disponível pode ser alocado entre horas de trabalho - que proporcionam a obtenção de salário - e horas de lazer, o trabalhador escolherá a combinação de salário e lazer que maximize a sua utilidade conforme função (1).

$$
\mathrm{U}=\mathrm{f} \text { (salário, lazer, preferências) }
$$

Para Smith (1985), a taxa salarial contém uma série de elementos para a tomada de decisão de ambas as forças de oferta e demanda por trabalho, como a intensidade do serviço, a probabilidade de acidente, as tarefas insalubres ou as que geram desutilidade. 0 risco de acidente de trabalho é uma característica negativa do emprego, que é evitada a não ser que exista uma compensação salarial pelo risco, ou seja, em geral, os trabalhadores não apreciam o risco de se acidentar.

0 trabalhador (hipoteticamente racional), muitas vezes, defronta-se com a decisão de trabalho envolvendo um aspecto positivo financeiro e aspectos negativos não financeiros. Nessa hipótese, o trabalhador buscará maximizar a sua utilidade, envolvendo o salário e o risco, conforme equação (2). A utilidade do trabalhador é crescente com a taxa de salário $(\partial U / \partial w>0)$ e decrescente com as condições de risco de acidentes do trabalho $(\partial U / \partial r<0)$. Com efeito, w incorpora os preços implícitos desses riscos (r) atrelados ao exercício do emprego, denominados de diferenciais compensatórios.

$$
\text { Maximizar }\{\mathrm{U}=\mathrm{f}(\mathrm{w} ; \mathrm{r})\}
$$

Ao lugar geométrico de todas as combinações de salários e riscos a partir dos quais os agentes econômicos (trabalhadores) derivam a mesma utilidade denominamos de curvas de indiferença. 0 gráfico 1 ilustra o mapa de curvas de indiferenças associadas à equação (2) (JORGE, 2011). 
Gráfico 1: Mapa de indiferenças

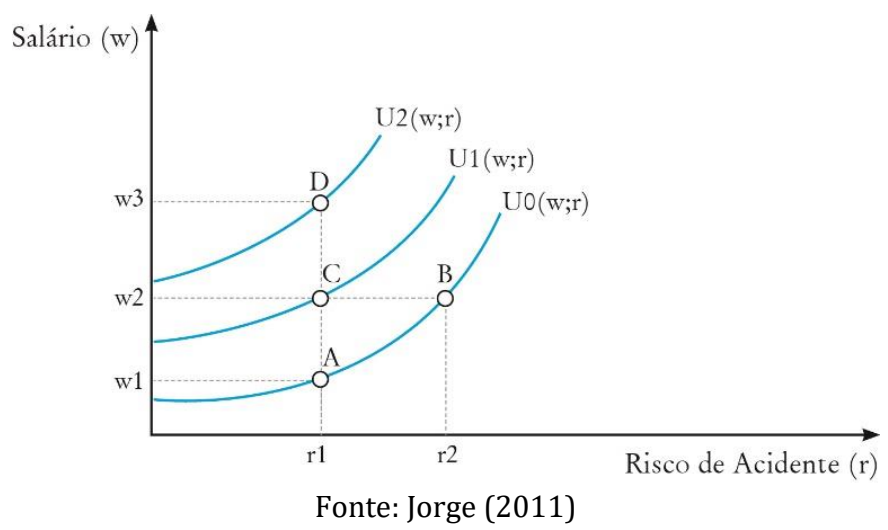

Uma vez que o salário mais alto para um nível de risco dado gerará maior utilidade, as curvas de indiferença apresentam maior utilidade à medida que se descolam em direção à noroeste do plano cartesiano. Essa situação pode ser explicada pelo axioma da não saciedade, ou seja, $U_{2}>U_{1}>U_{0}$, pois a combinação de $\left(w_{3} ; r_{1}\right)$ é preferível a $\left(w_{2} ; r_{1}\right)$, que é preferível a $\left(\mathrm{w}_{1} ; \mathrm{r}_{1}\right)$. Isso mostra o incremento na utilidade com o acréscimo de salário. Já para o risco, verificamos que $U_{1}>U_{0}$, pois a combinação $\left(w_{2} ; r_{1}\right)$ é preferível a $\left(w_{2} ; r_{2}\right)$, já que o aumento do risco, mantido o salário, resulta na redução da utilidade.

As pessoas, naturalmente, divergem em sua aversão à exposição a um risco ocupacional. Indivíduos muito sensíveis a esse risco irão requerer grandes aumentos salariais por qualquer aumento de risco, enquanto os menos sensíveis irão requerer aumentos salariais menores para manter a utilidade constante. Os trabalhadores sensíveis terão curvas de indiferença mais agudas (maior $\partial U / \partial r$ ) em qualquer nível de risco do que os trabalhadores menos sensíveis, conforme gráfico 2 .

Gráfico 2: Perfis de risco dos trabalhadores

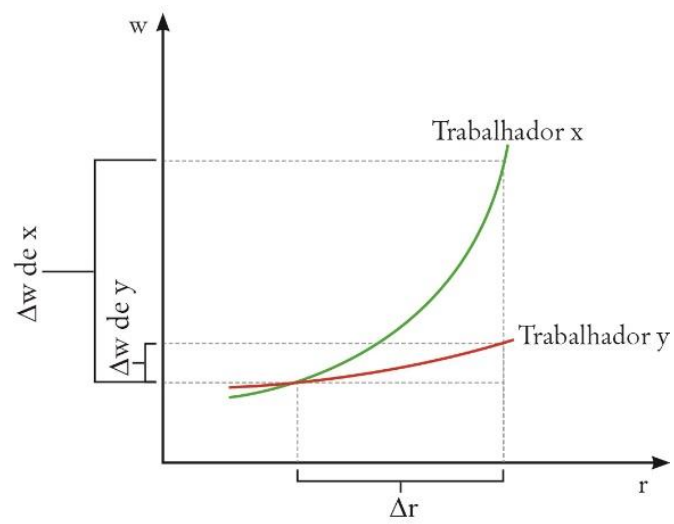

Fonte: Elaborado pelos autores 
Observe que para um aumento do risco no local de trabalho, o trabalhador $\mathrm{X}$ exige um salário muito maior do que o trabalhador $\mathrm{Y}\left(\Delta \mathrm{w}_{\mathrm{x}}>\Delta \mathrm{w}_{\mathrm{y}}\right)$. Para aquele, o risco é um atributo muito mais indesejado do que para este. Matematicamente, temos que o trabalhador $\mathrm{X}$ tem uma preferência maior pela renda (salário) do que pela minimização do seu risco, teoricamente, isso não significa que o trabalhador esteja submisso ao risco imposto pela empresa, mas apenas o quanto ele troca a sua segurança e integridade física por um maior salário.

Os empregadores, por sua vez, também enfrentam uma troca entre pagamento de salário e nível de risco de acidente, devido a três situações. Em primeiro lugar, é custoso reduzir os riscos de acidente enfrentados pelos funcionários, seja pela implantação de medidas de controle coletivas, administrativas ou individuais. Em segundo lugar, pressões competitivas presumivelmente obrigarão muitas empresas a operar sem lucros extraordinários, isto significa que as receitas cobrem apenas os custos e uma taxa de retorno justa. Por fim, todas as outras características do emprego são presumivelmente dadas ou já determinadas. E como consequência, se a empresa alocar muitos recursos para prevenção acabará reduzindo os salários. Por fim, Smith e Ehrenberg (2000) destacam que os empregadores diferem no custo com que podem eliminar os riscos de acidente de trabalho; assim, existem diversos perfis de isolucro.

Para a firma, há uma relação direta entre o risco do trabalho e o salário,representada pelas curvas de isolucro. A curva de isolucro define as combinações de salário e risco que produzem o mesmo nível de lucros para as empresas. As curvas a sudeste representam níveis de lucro mais altos porque para um dado nível de risco o salário é menor, e quanto menor for o gasto com salários e medidas de proteção, maior será o lucro.

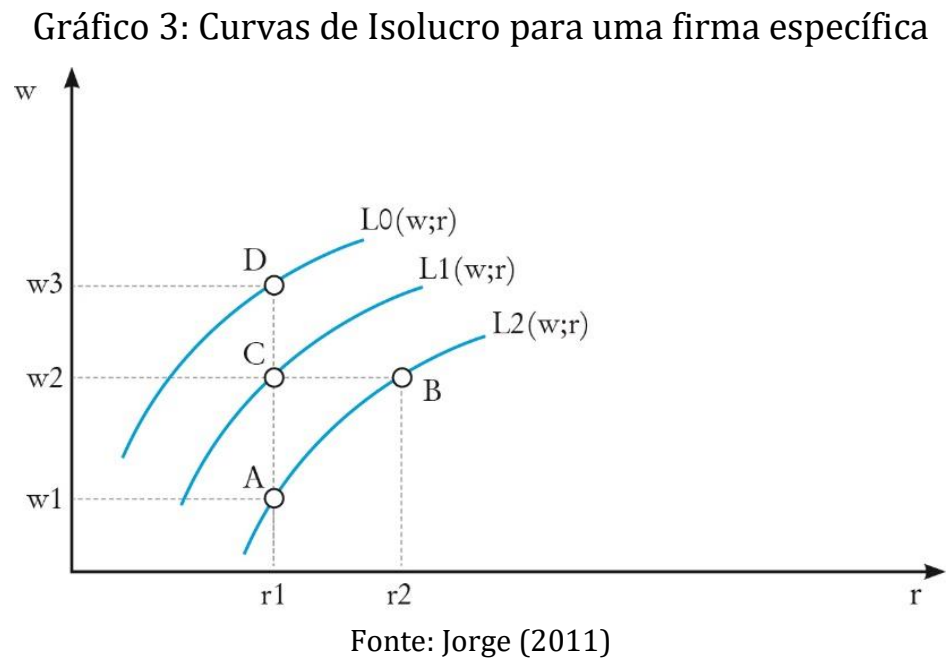


Segundo Jorge (2011), tomadas em conjunto todas as suposições relativas a trabalhadores e firmas, pode-se visualizar no gráfico 4 o equilíbrio do mercado de trabalho resultante. $\mathrm{O}$ trabalhador $\mathrm{X}$, mais avesso ao risco, maximiza $\mathrm{U}(\mathrm{w} ; \mathrm{r})$ empregando-se na firma $\mathrm{A}$, diferentemente do trabalhador $\mathrm{Y}$, que, devido às suas preferências de salário e risco, irá empregar-se na firma B. 0 modelo pode ser generalizado para um número maior de firmas e trabalhadores; é o que a teoria econômica denomina de matching (KAUFMAN; HOTCHKISS, 2006).

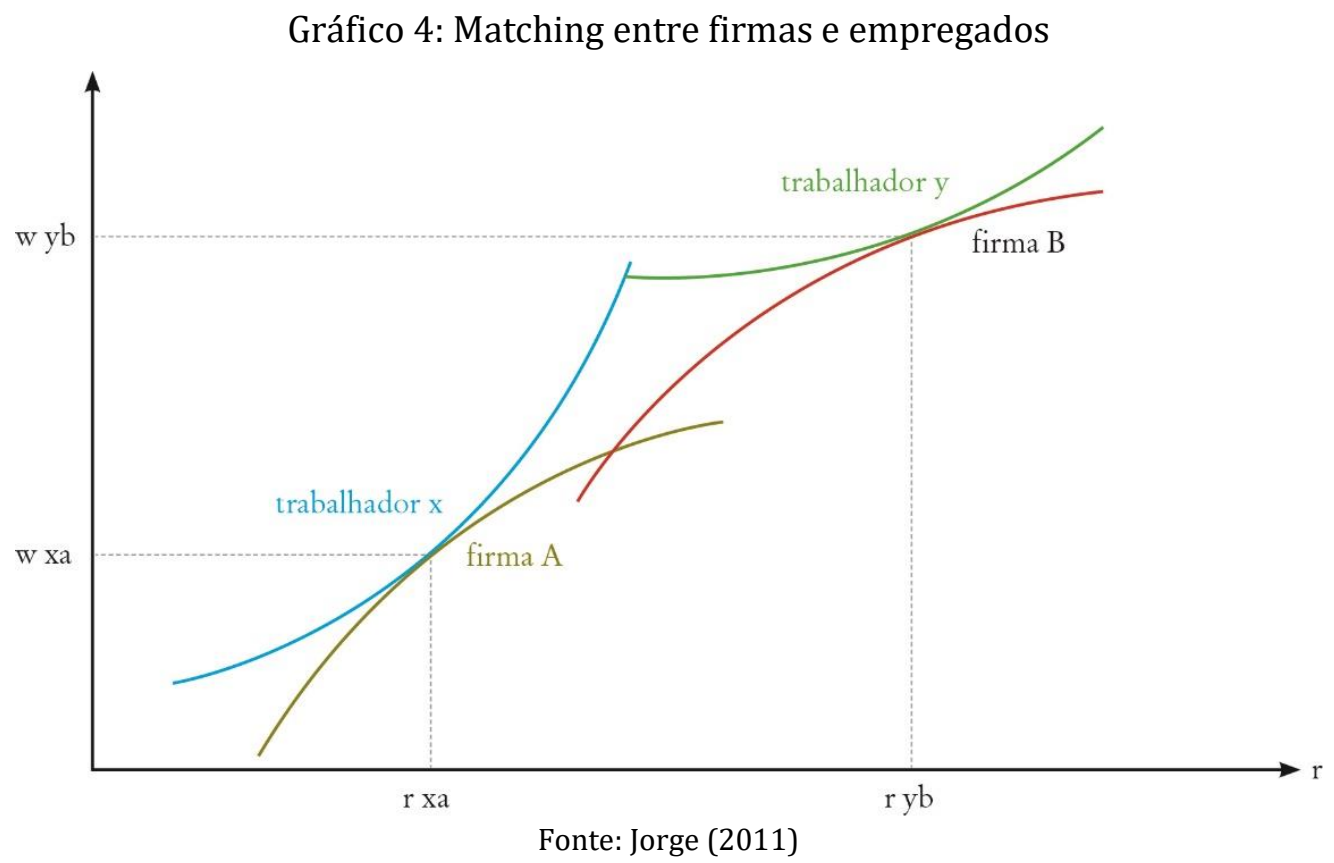

Para Smith e Ehrenberg (2000), o modelo gera duas percepções. A primeira é a de que os salários crescem com o risco, com os outros fatores mantendo-se constantes. De acordo com essa acepção, haverá diferenciais de salários compensatórios para as características de emprego vistas como indesejáveis pelos trabalhadores a quem os empregadores desejam atrair. Em segundo lugar, trabalhadores com fortes preferências pelo baixo risco tenderão a aceitar empregos em empresas onde é barato investir em segurança. Já os trabalhadores menos avessos ao risco buscarão e trabalharão por salários mais altos e riscos maiores. A segunda percepção é de que o processo de combinação de emprego (matching), além de não ser randômico, é aquele em que as empresas e os trabalhadores oferecem e aceitam o emprego de uma forma que obtém o máximo de suas utilidades e preferências, ocorrendo a maximização do bem-estar social. 
Segundo Jorge (2011), os diferenciais de salários compensatórios proporcionam uma indenização ex ante - relativa ao risco de acidente de trabalho, sujeição a doenças ocupacionais, como a asbestose, ou diminuição da capacidade física/orgânica, comoperda parcial da capacidade auditiva ${ }^{6}$. A Carta Magna e a legislação trabalhista no Brasil captaram esse fundamento econômico nos adicionais de insalubridade, periculosidade e penosidade. Contudo, a sua generalização proporciona falhas quanto à indenização do risco e à gradação do pagamento.

\subsection{Marco Legal: insalubridade no Brasil}

0 direito à compensação financeira pela exposição nociva à saúde ou à integridade física (diferenciais compensatórios da Teoria Econômica) e o direito à reparação financeira pelo dano acidentário são apenas alguns dos direitos garantidos pela Constituição Federal brasileira (CF) relacionados à exposição dos trabalhadores aos riscos inerentes ao trabalho. Segundo Oliveira (2011), a saúde do trabalhador com base na Constituição se conecta com suportes jurídicos da Consolidação das Leis Trabalhistas (CLT) e nas Normas Regulamentadoras (NRs) do Ministério do Trabalho e Emprego.

No Brasil, o pagamento pecuniário de diferenciais compensatórios pelo risco ocorre pelos adicionais de insalubridade, periculosidade e penosidade, conforme previsão constitucional. 0 adicional de penosidade encontra-se previsto no art. 7으, inciso XXIII, da CF-88, inserido no mundo jurídico com os adicionais de periculosidade e insalubridade.

A periculosidade envolve atividades perigosas que, por sua natureza ou método de trabalho, impliquem risco acentuado em virtude de exposição permanente do trabalhador a explosivos, inflamáveis, energia elétrica, radiação ionizante, roubos ou outras espécies de violência física nas atividades de segurança pessoal ou patrimonial (OLIVEIRA, 2011). 0 exercício de trabalho em condições de periculosidade assegura a percepção de adicional de 30\% (trinta por cento), incidente sobre o salário, sem os acréscimos resultantes de gratificações, prêmios ou participação nos lucros da empresa.

A penosidade está relacionada às situações com as quais se lida e que comportam uma carga psicológica perturbadora, desconforto, alteração dos

6 Diferentemente da indenização expost, paga após a ocorrência de um evento, como o auxílio acidente pago pela previdência social em caso de afastamento do trabalhador. Tal benefício, no entanto, tende a ser incompleto devido à existência de um teto monetário e a não compensação por eventuais custos psicológicos ao trabalhador, justificando, assim, a existência da indenização exante, conforme Jorge (2011). 
ritmos biológicos: aquilo que exige um esforço físico, psicológico, social, espiritual, permanente e suplementar. No entanto, a penosidade nunca foi regulamentada na esfera trabalhista para fins de adicionais compensatórios (OLIVEIRA, 2011).

A insalubridade é um atributo do local de trabalho ou da atividade laboral que tem por característica principal a criação de risco ou potencialidade danosa à saúde do trabalhador. Para Oliveira (2011), a insalubridade foi um conceito capturado pela norma trabalhista para definição de acréscimo remuneratório para quem a ela se sujeitar, por força de mando, ao chamado poder direto do empregador. A insalubridade, tecnicamente, decorre de um nexo de causalidade entre o meio ambiente do trabalho e suas consequências para o trabalhador exposto. 0 adicional de insalubridade é algo distinto, que depende de formatação jurídica para existir. Assim, é possível que o ambiente seja prejudicial à saúde (insalubre, de perspectiva científica e técnica), mas sem ativação jurídica para o pagamento do adicional (SALIBA; CORRÊA, 2012).

Conforme Barbosa Filho (2011), a CLT estabeleceu que o exercício de trabalho em condições insalubres, acima dos limites de tolerância legais, assegura a percepção do adicional de respectivamente $40 \%, 20 \%$ ou $10 \%$ do salário mínimo da região, segundo se classifiquem nos graus máximo, médio ou mínimo. Por exemplo, a exposição ao ruído, ao estresse térmico e à vibração é caracterizada de risco médio, enquanto os agentes químicos podem ser de grau mínimo (acetona), médio (metil etil cetona) ou máximo (clorobenzeno). A exposição ao risco simplificada em três níveis de pagamento pode gerar uma falsa informação no mercado de trabalho (tanto para empregadores quanto trabalhadores) de que existem somente três níveis de risco para o trabalhador: um pequeno, um moderado e um grande, o que não é verdade.

A legislação trabalhista definiu como atividades ou operações insalubres aquelas que, por sua natureza, condições ou métodos de trabalho, exponham os trabalhadores ou empregados a agentes nocivos à saúde, acima dos limites de tolerância fixados em razão da natureza e da intensidade do agente e do tempo de exposição aos seus efeitos (artigo 192 da CLT). Já o Ministério do Trabalho e Emprego, através da NR-15, estabeleceu três critérios para a caracterização legal da insalubridade: avaliação quantitativa, avaliação qualitativa e avaliação qualitativa dos riscos inerentes à atividade.

$\mathrm{Na}$ avaliação qualitativa, a insalubridade é constatada por meio de inspeção realizada no local de trabalho, ou seja, para os agentes que possuem esse tipo de avaliação, não foram fixados limites de tolerância (quantitativos). São avaliados, dessa forma, os agentes: radiações não ionizantes, frio, umidade e parte dos agentes químicos (SALIBA; CORRÊA, 2012). Diferentemente, na avaliação qualitativa dos riscos inerentes à atividade, quando não se há meios de eliminar 
ou neutralizar a insalubridade, significa que esta é inerente à atividade, ou seja, o risco não pode ser totalmente eliminado com medidas no ambiente de trabalho ou como uso de equipamentos de proteção individual (EPI). Enquadram-se nessa situação as condições hiperbáricas, parte dos agentes químicos e os agentes biológicos (SALIBA; CORRÊA, 2012).

Por fim, a avaliação quantitativa define os limites de tolerância para os agentes ambientais fixados em razão da sua natureza, intensidade e tempo de exposição. Os agentes avaliados quantitativamente são o ruído, o calor, as radiações ionizantes, as vibrações, parte dos agentes químicos e as poeiras minerais. Atualmente no Brasil, muitas avaliações quantitativas são realizadas contrariando as metodologias e as normas técnicas, quando não são simplesmente tratadas de forma qualitativa, ou seja, negligenciadas. Apenas engenheiros e médicos do trabalho estão autorizados e aptos para realizar avaliações quantitativas para fins de insalubridade (OLIVEIRA, 2011).

0 direito ao adicional de insalubridade depende da previsão legal, ou seja, não basta que uma situação seja passível de causar dano ao trabalhador, esta terá que estar definida em uma norma. Pela norma atual, retratada no gráfico 5 , se o risco for maior que o limite de tolerância, paga-se o adicional de insalubridade. Contudo, observa-se que o pagamento pela exposição é uniforme (não há elevação pelo maior risco) e que o risco e seu limite de tolerância devam estar previstos na legislação.

Gráfico 5: Pagamento de insalubridade por avaliação quantitativa

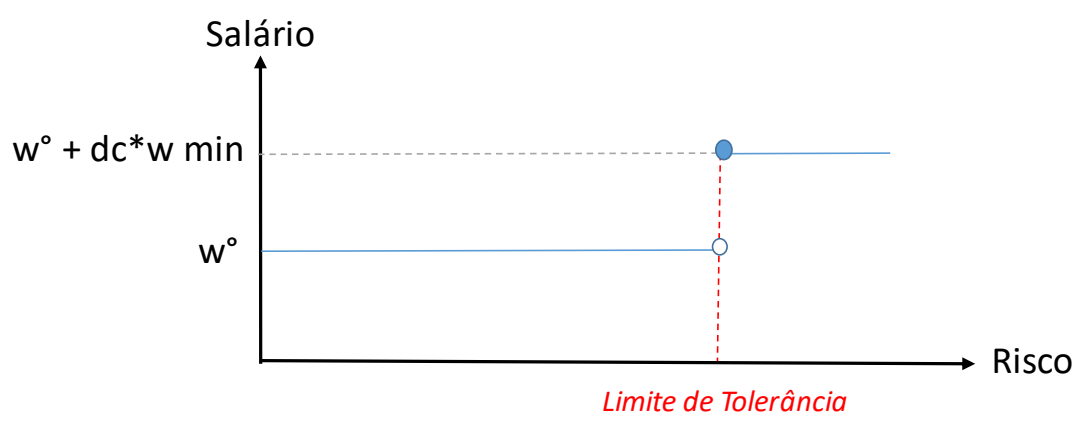

$d c=\{10 \% ; 20 \% ; 40 \%\}$

Fonte: Elaborado pelos autores 
Assim, sobre o salário base do trabalhador $\left(\mathrm{w}^{0}\right)$, será pago um diferencial compensatório (dc) equivalente a $10 \%, 20 \%$ ou $40 \%$ do salário mínimo (dc*wmin), conforme o grau de insalubridade presente no ambiente de trabalho.

Por fim, há duas formas de eliminar ou neutralizar a insalubridade: com a adoção de medidas que conservem o ambiente de trabalho dentro dos limites de tolerância e com a utilização de EPIs pelo trabalhador que diminuam a intensidade do agente agressivo ao limite de tolerância. Essa eliminação ou neutralização ficará caracterizada conforme avaliação assinada por engenheiro ou médico do trabalho (SALIBA; PAGANO, 2010). Isso significa que a obrigação ao pagamento do diferencial compensatório some com a eliminação ou neutralização.

Atualmente, muitos trabalhadores recorrem à Justiça do Trabalho para receber pagamentos de insalubridade que deveriam ter sido pagos e não o foram, mesmo sem ter ocorrido nenhum dano ou doença. Segundo Pereira (2015), a conceituação da insalubridade se vincula a uma situação de risco ou de potencialidade danosa à saúde do trabalhador. Assim, não é necessário para que se caracterize insalubridade o dano efetivamente ocorrido, trata-se de um diferencial compensatório nos salários por uma possibilidade de dano.

\subsection{0 risco físico ruído}

O ruído é um fenômeno físico vibratório que, no caso da Acústica, indica uma mistura de sons, cujas frequências não seguem uma regra precisa. Sendo também uma das formas de poluição e de riscos mais frequentes nos ambientes laborais, principalmente locais intensivos em mão de obra como indústria, construção civil e mineração. A exposição ao ruído pode gerar diversos efeitos no organismo humano, dentre os quais se destacam a Pairo (perda auditiva induzida pelo ruído), o incremento da pressão arterial e da frequência cardíaca e respiratória, os distúrbios do sono e outras alterações de natureza neuropsíquica, dentre outros problemas (PEREIRA, 2015).

No Brasil, a exposição ao ruído consiste em uma das maiores fontes de pagamento de adicionais de insalubridade para trabalhadores, sem contar os processos indenizatórios em fase da Previdência Social ou de responsabilidade civil (PEREIRA, 2015). Para os profissionais de engenharia de segurança e medicina do trabalho é um dos riscos mais presentes e comumente mitigados, presentes desde o mais complexo ao mais simples empreendimento.

0 risco da lesão auditiva cresce com o nível de pressão sonora e com a duração da exposição, mas depende também das características do ruído, sem falarmos da suscetibilidade individual. 0 nível de pressão sonora (NPS) determina a intensidade do som e representa a relação do logaritmo entre a variação da pressão (em pascal $\mathrm{Pa})$ provocada pela vibração e a pressão que atinge o limiar de audibilidade $(0,00002$ 
Pa). A equação no nível de pressão sonora (NPS), dado em uma escala dB, é representada abaixo (MIGUEL, 2007).

$$
\text { Nível de Pressão Sonora }=20 \log \left[\frac{P(P a)}{0,000002 P a}\right]
$$

Por exemplo, para uma conversa normal, temos uma variação de NPS de 55 a $70 \mathrm{~dB}$, enquanto que, para um avião a jato, temos $140 \mathrm{~dB}$. A tabela 1 ilustra alguns exemplos de fonte de ruído e os respectivos níveis de pressão sonora. Na prática, os níveis de ruído são mensurados diretamente através de equipamentos de medição como o decibelímetro e o audiosímetro.

Tabela 1: Níveis de pressão sonora comuns

\begin{tabular}{cc}
\hline Fonte de Ruído & NPS (dB) \\
\hline Avião a jato & 140 \\
Rebitadeira Automática & 130 \\
Trovão & 120 \\
Metrô & 90 \\
Tráfego & 80 \\
Conversação Normal & 60 a 70 \\
Quarto à noite & 25 a 35 \\
\hline
\end{tabular}

Fonte: Miguel (2007)

O ruído será considerado um agente insalubre, passível de causar danos à saúde do trabalhador, se estiver acima dos limites previstos no Anexo 1 da NR-15 (tabela 2). Para MIGUEL (2007), o limite de tolerância representa as condições para as quais se acredita que a maioria dos trabalhadores expostos repetidamente não sofra efeitos adversos à sua capacidade de ouvir e entender uma conversação normal. No Brasil, o exercício de trabalho em condições de insalubridade relacionadas ao ruído, assegura ao trabalhador a percepção do adicional, incidente sobre o salário mínimo da região, equivalente a $20 \%$ deste. Os limites relacionados ao tempo de exposição encontramse na tabela 2 abaixo. 
Tabela 2: Limites de tolerância para ruído (NR-15)

\begin{tabular}{|c|c|}
\hline $\begin{array}{c}\text { NÍVEL DE RUÍDO } \\
\text { DB (A) }\end{array}$ & $\begin{array}{l}\text { MÁXIMA EXPOSIÇÃO DIÁRIA } \\
\text { PERMISSÍVEL }\end{array}$ \\
\hline 85 & 8 horas \\
\hline 86 & 7 horas \\
\hline 87 & 6 horas \\
\hline 88 & 5 horas \\
\hline 89 & 4 horas e 30 minutos \\
\hline 90 & 4 horas \\
\hline 91 & 3 horas e 30 minutos \\
\hline 92 & 3 horas \\
\hline 93 & 2 horas e 40 minutos \\
\hline 94 & 2 horas e 15 minutos \\
\hline 95 & 2 horas \\
\hline 96 & 1 hora e 45 minutos \\
\hline 98 & 1 hora e 15 minutos \\
\hline 100 & 1 hora \\
\hline 102 & 45 minutos \\
\hline 104 & 35 minutos \\
\hline 105 & 30 minutos \\
\hline 106 & 25 minutos \\
\hline 108 & 20 minutos \\
\hline 110 & 15 minutos \\
\hline 112 & 10 minutos \\
\hline 114 & 8 minutos \\
\hline 115 & 7 minutos \\
\hline
\end{tabular}

Fonte: Ministério do Trabalho 
Conforme tabela 2, o risco de perda auditiva envolve não apenas a intensidade, mas também o tempo de exposição. Quando o nível de ruído é variável durante a jornada de trabalho, há necessidade de calcular a dosimetria ou o efeito combinado conforme anexo 1, item 6, da Norma Regulamentadora n. 15 do Ministério do Trabalho de forma que a soma das frações abaixo resultará em um nível equivalente de ruído. Conceitua-se dose de ruído a porcentagem de energia sonora referente à jornada de trabalho, tendo por referência o valor máximo de energia sonora máxima admitida.

$$
\sum_{i=1}^{n} \frac{C i}{T i}=\text { dose }
$$

Sendo Ci o tempo total de exposição do trabalhador a um determinado nível de ruído e Ti a máxima exposição diária permissível a um nível de ruído i,quando a dose for maior que 1 ou 100\%, considera-se insalubre o ambiente. A NR-09, que regula o gerenciamento dos riscos do ambiente de trabalho, determina que a dose maior que 0,5 ou $50 \%$ exige o início de ações preventivas de forma a minimizar a probabilidade de que as exposições a agentes ambientais ultrapassem os limites de exposição. As ações devem incluir o monitoramento periódico da exposição, a informação aos trabalhadores e o controle médico.

Quando a dose estiver entre 0,8 e 1, temos a denominação técnica de zona de incerteza, que demanda a adoção de medidas preventivas e corretivas visando a redução da dose diária. Por fim, quando a dose diária for maior do que 1, temos uma exposição maior do que o limite legal, sendo recomendada a adoção imediata de medidas corretivas e obrigatório o pagamento do adicional de insalubridade. Com base no resultado da dose de ruído e por meio da equação abaixo, obtém-se o nível equivalente de ruído, se o NPS equivalente for maior que $85 \mathrm{~dB}$ temos a caracterização da insalubridade.

$$
\text { NPS equivalente }=85+16,61 \log \left(\text { dose } * \frac{8}{\text { tempo de exposição }(h)}\right)
$$

Por exemplo, supondo que um trabalhador de determinada indústria intensiva de capital esteja exposto a um ruído de $100 \mathrm{~dB}$ durante 40 minutos, de $90 \mathrm{~dB}$ durante 2 horas e a $80 \mathrm{~dB}$ durante o resto do tempo, a dose de ruído será de $\frac{40 \mathrm{~min}}{60 \mathrm{~min}}+\frac{2 h}{4 h^{\prime}}$ ou seja, 1,1667.0bserva-se que,para fins de cálculo de dose, só foram computados os valores maiores que $85 \mathrm{~dB}$ e que o resultado é sempre um número adimensional. Conforme a equação (5), tem-se um nível de ruído equivalente de $86,1 \mathrm{~dB}$ e a caracterização de insalubridade, situação representada na prática pelo gráfico 6 . 
Gráfico 6: A lógica da dosimetria na avaliação de ruído
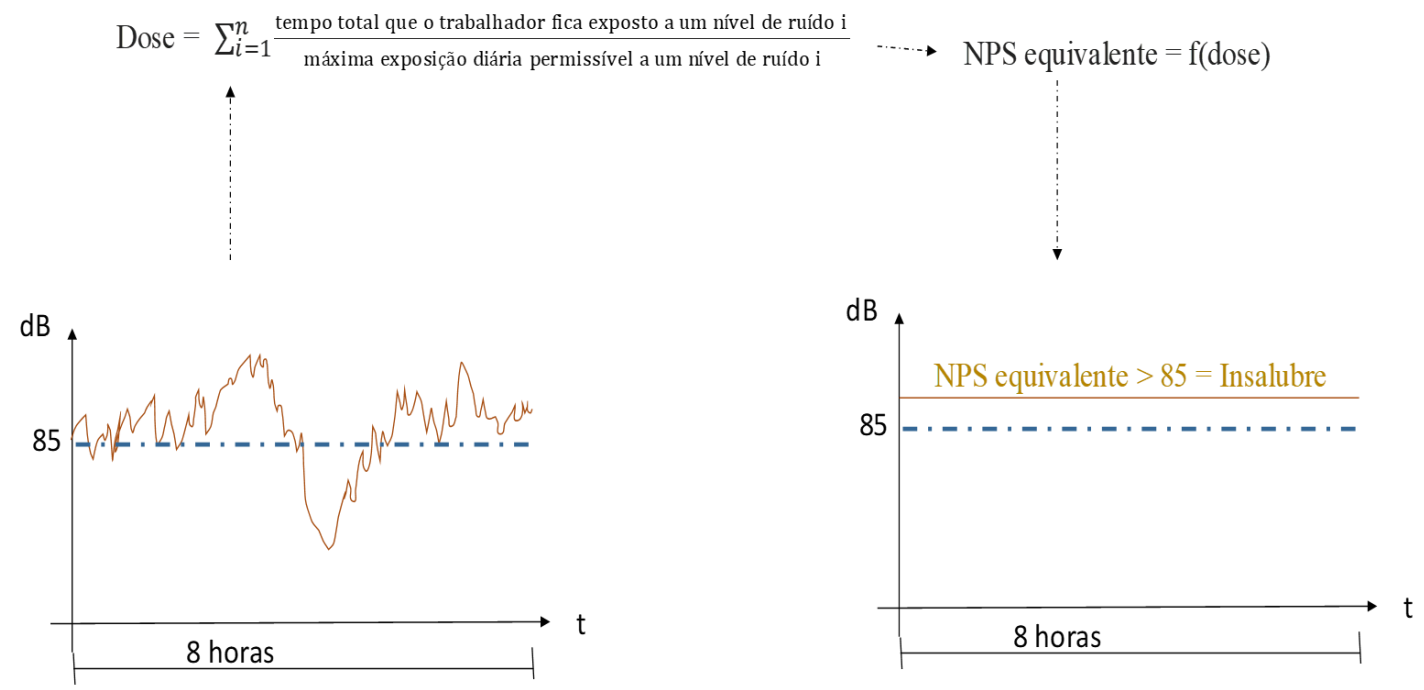

Fonte: Elaborado pelos autores

Segundo Saliba e Correa (2012), o ruído pode ser controlado de três formas: na fonte, na trajetória e no homem. 0 controle na fonte é o método mais recomendado quando há viabilidade técnica, por exemplo: alterar o processo substituindo a máquina ruidosa por outra silenciosa. Não sendo possível o controle na fonte, o segundo passo é a verificação de possíveis medidas a serem aplicadas no meio ou na trajetória. A medida clássica na trajetória é o isolamento acústico via enclausuramento. Por fim, como medidas de controle no trabalhador podem-se enumerar a limitação do tempo de exposição, que reduz a dose e consequentemente o nível de pressão sonora equivalente, e o uso de equipamentos de proteção individual (protetores auriculares).

\section{Aplicação do modelo proposto: discussão}

Conforme visto na seção 2, os trabalhadores possuem perfis diferentes relacionados ao risco e ao salário requerido para sua exposição. 0 pagamento de adicionais fixos de $10 \%, 20 \%$ ou $40 \%$ vai de encontro com essas preferências dos riscos relacionados aos salários. Matematicamente, com a adoção de um diferencial único $(0,2 *$ Wmin $)$, cada trabalhador terá apenas um ponto justo. Pelo gráfico 7, o trabalhador $\mathrm{X}$, avesso ao risco, embora seja beneficiado pela legislação até um nível de exposição $\mathrm{r}^{\prime}$, não estaria maximizando sua utilidade quando o risco fosse maior que $r^{\prime}$, pois somente 
por um diferencial maior ele aceitaria trabalhar sobre talnível de risco. 0 trabalhador $Y$, no caso, estaria recebendo um salário maior do que o seu perfil de risco demanda (para $r$ $<r^{\prime \prime}$ ), não proporcionando às empresas a possibilidade de uma negociação para minimizar os custos. A regulamentação atual aumenta o bem-estar de parte dos trabalhadores, mas reduz o bem-estar de outra parte, ocorrendo, assim, uma possível perda de eficiência do mercado de trabalho (SMITH; EHRENBERG, 2000; CAHUC; ZYLBERBERG, 2004).

Gráfico 7: Diferenciais compensatórios para exposição ao ruído no Brasil

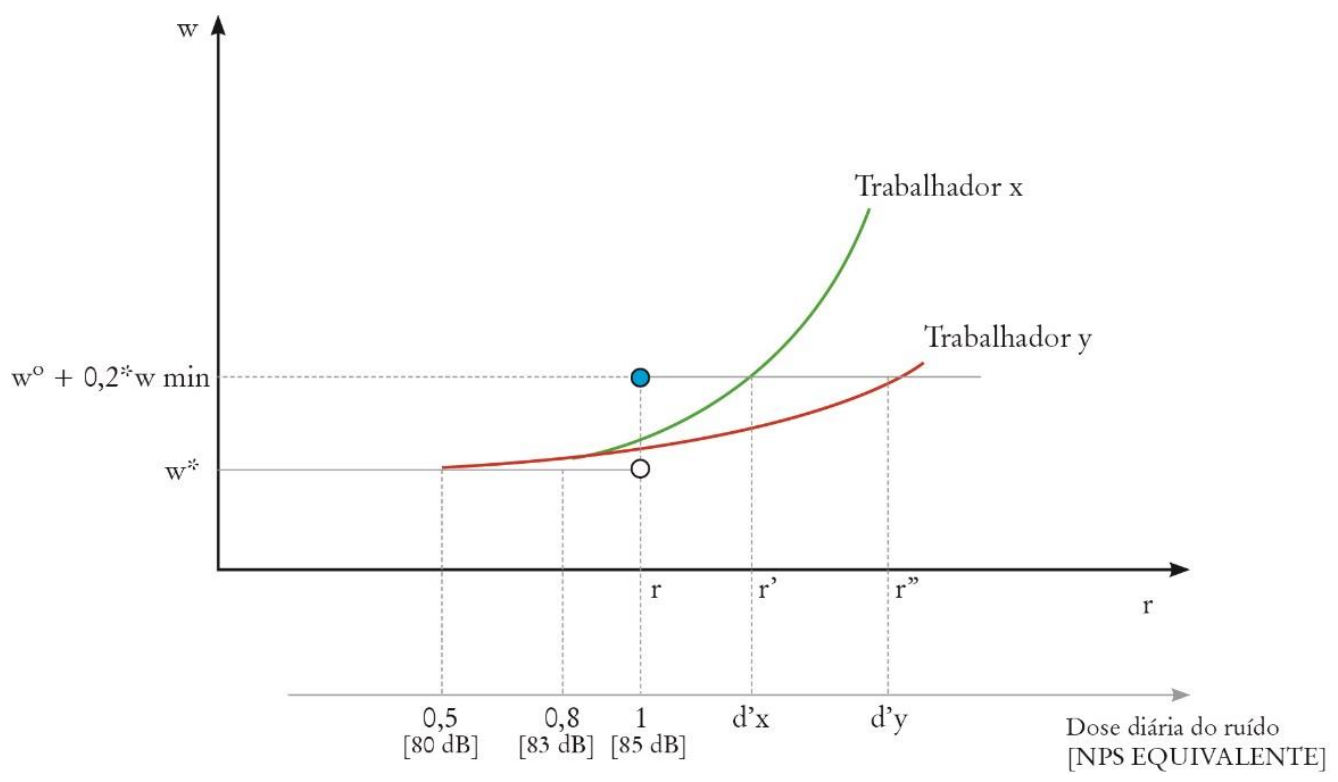

Fonte: Elaborado pelos autores

Essa decisão binária de pagar ou não o adicional de insalubridade, ocorre somente se a dose for maior que uma unidade (ruído equivalente maior ou igual a 85 $\mathrm{dB}$ ). Acredita-se que esse seja o valor que comece a criar uma probabilidade de causar agravos à saúde do trabalhador, uma situação de risco. Contudo, as próprias legislações de segurança e medicina do trabalho obrigam as empresas a tomarem medidas de controle quando a dose for maior que 0,5 (ruído maior que $80 \mathrm{~dB}$ ). Há com isso uma evidência de algum risco ao trabalhador, mesmo que não haja previsão legal para pagamento de insalubridade. Antes de 04/03/97 (início da vigência do Decreto 53.831) o ruído equivalente acima de $80 \mathrm{~dB}$ era usado pela Previdência Social para concessão de aposentadoria especial.

Outro grande problema está relacionado à escala do ruído. Por exemplo, um ruído de $90 \mathrm{~dB}$ só é considerado insalubre se o trabalhador estiver exposto por mais 
de 4 horas por dia, mas se este ficar 8 horas exposto, estará sujeito a uma intensidade duas vezes maior do que se estivesse sujeito a $85 \mathrm{~dB}$ devido à escala logarítmica. Assim, há situações industriais em que os trabalhadores estão expostos a níveis equivalentes de $95 \mathrm{~dB}$, um valor $300 \%$ mais intenso. 0 problema é que todos os trabalhadores receberão os mesmos $20 \%$ de adicional de insalubridade.

Assumindo que os trabalhadores são racionais e que conhecem as suas preferências, conforme a teoria exposta na seção 2.1, aqueles mais avessos aos riscos somente aceitariam trabalhar em certas situações se o valor do salário compensasse a desutilidade da situação. Supondo, respectivamente,quatro trabalhadores com diferentes perfis de risco, expostos pela firma " $A$ " a um ruído acima de $85 \mathrm{~dB}$, o equilíbrio será diferente para cada um dos trabalhadores, conforme apresentado no gráfico 8. Verifica-se que a empresa pagará a dois funcionários um diferencial compensatório maior do que estes aceitariam receber e aos outros dois um diferencial menor do que estes aceitariam.

Gráfico 8: Inconsistência econômica do adicional fixo

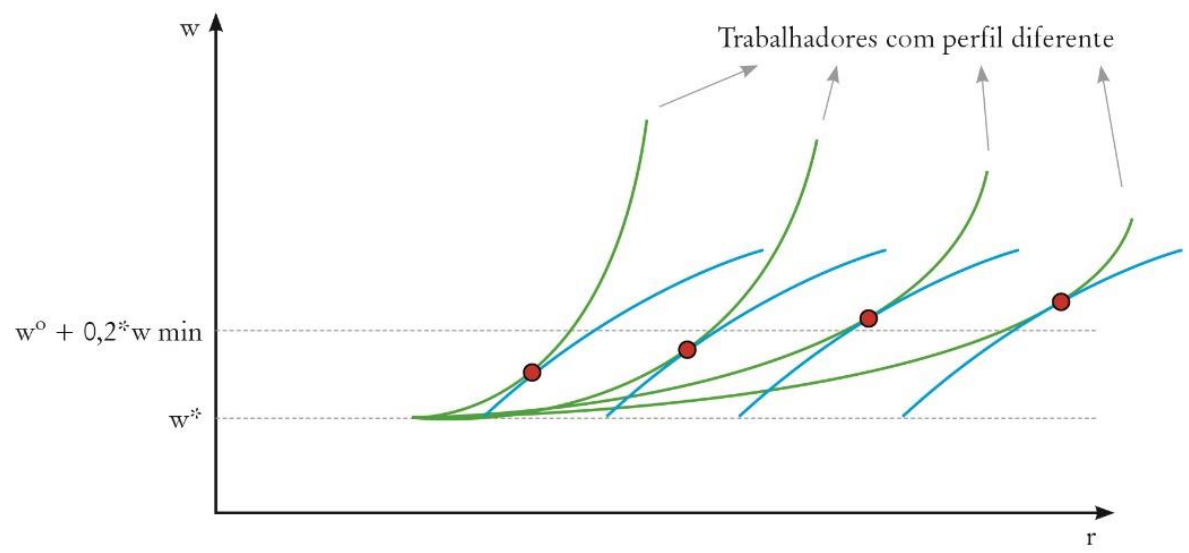

Fonte: Elaborado pelos autores

O trabalhador tende a subestimar os riscos pequenos e o ruído é um vilão oculto. Às vezes, preocupa-se muito com riscos químicos, como óleos, gases e vapores e deixa o ruído de lado pelo fato de estar usando proteção individual. Podem existir situações em que o trabalhador se torna propenso ao risco simplesmente por não conhecer os efeitos de longo prazo da exposição. Outro fator para propensão ao risco é a tendência dos indivíduos de ignorar informações negativas (JORGE, 2011).

Assim, a hipótese da informação perfeita a respeito de riscos ocupacionais padece de falta de suporte empírico, já que, conforme Leigh e Gill (1991, p. 734) somente "aproximadamente $5 \%$ das trabalhadoras estavam plenamente informadas dos riscos de seu próprio emprego". Também Rodrigues (2001), com uma amostra 
composta por funcionários de empresas terceirizadas que prestam serviço a hospitais de grande porte do município de São Paulo, fornece indícios de subestimação dos riscos por parte destes: apenas $8 \%$ dos entrevistados fazia uso das medidas de proteção aplicáveis, mas entre $12 \%$ e $18 \%$ da amostra já haviam sofrido algum tipo de acidente de trabalho. Assim, torna-se difícil na prática para um trabalhador saber qual seria o seu "salário justo" para determinado risco.

Em situações de informação imperfeita a regulamentação pode surgir como solução para melhorar o bem-estar dos trabalhadores. Com isso, a seguir, propõese um modelo que relaciona a dose de ruído com o pagamento do diferencial compensatório.

0 modelo proposto busca resolver os três problemas encontrados na atual norma jurídica brasileira: (1) não há distinção entre o diferencial compensatório (adicional de insalubridade) e os diferentes níveis de risco (dose); (2) não são considerados os níveis de ruído entre 80 e 85 dB e (3) não há equilíbrio entre as firmas e os empregados e consequentemente não há maximização do bem-estar social. Para a concepção do modelo temos os seguintes pressupostos:

- Não há a entrega de equipamentos de proteção individual para mitigação do risco;

- $\quad 0$ ruído possui frequência entre 3000 e $6000 \mathrm{~Hz}$ (maior audibilidade);

- O pagamento de insalubridade começa com o ruído equivalente acima de $80 \mathrm{~dB}$. Dessa forma, consideramos este ponto o menor pagamento possível: $10 \%$ sobre o salário mínimo da região. 0 adicional de insalubridade cresce de forma exponencial de $10 \%$ até o valor de $20 \%$ para um ruído equivalente de $85 \mathrm{~dB}$. Fazendo a interpolação exponencial em termos de dose temos que: adicional $=0,05 \mathrm{e}^{1,3863^{*} \text { dose }}$.

- O pagamento para um ruído equivalente de $85 \mathrm{~dB}$ mantém-se em $20 \%$ de acordo com as normas vigentes atualmente (2018). Contudo, considerando que o pagamento máximo na legislação é de $40 \%$ e que uma dose 5 representa um valor expressivamente alto, realiza-se o mesmo raciocínio acima para encontrarmos: adicional $=0,168 \mathrm{e}^{0,1733^{*} \text { dose }}$

Assim temos o modelo proposto de diferenciais compensatórios (dc) para ruído ocupacional baseado na dose de exposição reassentado pelas equações (6), (7) e (8).

$$
\begin{gathered}
\mathrm{dc}=(\text { salário mínimo })^{*} 0,05 \mathrm{e}^{\left(1,3863^{*} \mathrm{dose}\right)} \text { para } 0,5<\mathrm{dose}<1 \\
\mathrm{dc}=(\text { salário mínimo })^{*} 0,168 \mathrm{e}^{\left(0,1733^{*} \mathrm{dose}\right)} \text { para } 1 \leq \mathrm{dose} \leq 5 \\
\mathrm{dc}=(\text { salário mínimo })^{*} 0,4 \text { para dose }>5
\end{gathered}
$$


Esse modelo cria a relação adicional/dose que tenderia a ser mais justa não apenas com os trabalhadores, mas também com as firmas. 0 gráfico 9 ilustra a síntese do novo modelo, o "casamento" (matching) entre vários trabalhadores e um conjunto de empresas existentes em um determinado mercado. Na antiga regulamentação (linha horizontal) não havia o máximo bem-estar, mas com a nova regulamentação (conjunto de três curvas) há um incremento: o do bem-estar e a redução da ineficiência do mercado de trabalho.

\section{Gráfico 9: Modelo para Pagamento de Insalubridade - Ruído}

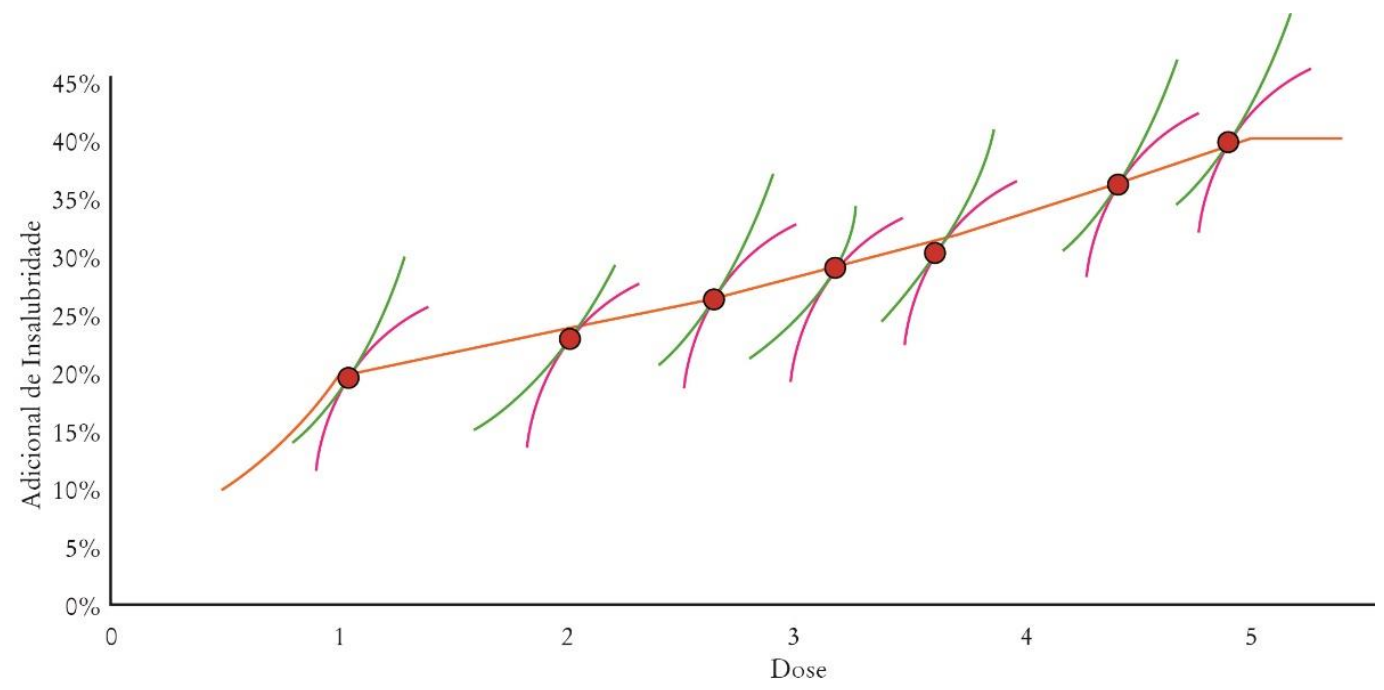

Fonte: Elaborado pelo autor

Um dos pontos fundamentais para a implementação desse modelo é a elaboração dos laudos técnicos sob a responsabilidade de engenheiros ou médicos do trabalho e a fiscalização contínua de todos os agentes públicos envolvidos, como os Auditores Fiscais do Trabalho. Com a adoção desse critério, cria-se o risco de que as avaliações sejam manipuladas para reduzir o custo de mão-de-obra, por isso é fundamental não apenas a fiscalização, mas a responsabilidade civil e criminal dos responsáveis técnicos pelos laudos. Assim, acredita-se que esse modelo possa ser melhor implementado por empresas que negociam com sindicatos organizados do que naquelas que não os possuem. 


\section{Considerações finais}

O objetivo do presente artigo foi o de elaborar, baseado na teoria dos diferenciais compensatórios de salário, uma nova forma de pagamento do adicional de insalubridade para ruído no Brasil. 0 modelo buscou distinguir o diferencial compensatório (adicional) de acordo com a dose de ruído, fazendo maior justiça aos agentes econômicos. Outra característica foi ter incluído os níveis de pressão sonora entre 80 e $85 \mathrm{~dB}$, como uma variação da insalubridade de grau mínimo ao grau médio $(10 \%$ a $20 \%)$. Por fim, o modelo mostrou que melhor se adequa a um matching eficiente entre firmas e trabalhadores.

Assim, a contribuição do presente artigo consiste na proposição de um modelo de pagamento de adicional de insalubridade que reduza as ineficiências do mercado de trabalho, possibilitando um aumento de bem-estar de empresas e de trabalhadores, especialmente destes últimos, a quem a norma objetiva proteger.

Trata-se de um trabalho interdisciplinar, abrangendo as diversas áreas que envolvem as relações de trabalho: a Economia do Trabalho, o Direito do Trabalho, a Engenharia de Segurança do Trabalho e a Medicina do Trabalho.

Uma limitação do presente estudo é que este se restringe ao adicional de insalubridade referente ao ruído. Dessa maneira, futuros trabalhos poderiam incluir outros agentes de risco como calor, radiação ionizante, poeiras minerais, vapores, pressões hiperbáricas, dentre outros, seguindo a mesma linha de raciocínio aqui adotada. Todos estes agentes ainda possuem um valor fixo de adicional de insalubridade, que poderia ser modelado de acordo com o nível de risco e não apenas após ultrapassado o limite de tolerância.

Outra limitação é a de que o trabalho não questiona a existência dos adicionais de insalubridade, que representam uma compensação monetária pela exposição ao risco. Considerando-se o fato de que a legislação norte-americana e europeia não preveem qualquer tipo de adicional e sim a adequação do ambiente de trabalho, pesquisas futuras poderiam incorporar uma discussão de cunho ético/moral sobre a pertinência dos adicionais.

\section{Referências}

BARBOSA FILHO, A. N. Segurança do Trabalho \& Gestão Ambiental. 4ª ed. São Paulo: Atlas, 2011.

BLACK, D.A.; KNIESNER, T. J. On the Measurement of Job Risk in Hedonic Wage Models. The Journal of Risk and Uncertainty, v. 27, n.3, 2003, p. 205-220. DOI: https://doi.org/10.1023/A:1025889125822 
BRASIL. (legislação). Constituição da República Federativa do Brasil, 1988. Brasília: Senado Federal, 1988.

BRASIL. (legislação). Decreto-Lei 5.452 de 1‥ de maio de 1943. Consolidação das Leis do Trabalho. In: http://www.planalto.gov.br/ccivil_03/decreto-lei/Del5452.htm, Acessado em: 24/08/16.

CAHUC, P.; ZYLBERBERG, A. Labor Economics. Cambridge: MIT Press, 2004.

FUNDACENTRO. Norma de Higiene Ocupacional NHO-01: Procedimento técnico: Avaliação da exposição ocupacional ao ruído. São Paulo: Fundacentro, 2001

HARTLEY, P.; STRASSMANN, D. Wage differentials and asymmetric mobility. Social Science Journal, v. 27, n. 2, 1990, p. 159-181. DOI: https://doi.org/10.1016/03623319(90)90034-H

JEHLE, G. A.; RENY P. J. Advanced Microeconomic Theory. $3^{\text {th }}$ ed. London: Pearson, 2011.

JORGE, M. A. Economia do Trabalho: Diferenciais Compensatórios de Salário e Taxas de Homicídio no Brasil. Aracaju: Editora UFS, 2011.

KAUFMAN, B.; HOTCHKISS, J. The Economics of Labor Markets. 7 ed. Mason: Thomson, 2006.

KNIESNER, T. J.; LEETH, J. D. Compensating Wage Differentials for Fatal Injury Risk in Australia, Japan, and the United States. Journal of Risk and Uncertainty, v. 4, 1991, p. 75-90. DOI: https://doi.org/10.1007/BF00057887

LEIGH, J. P.; GILL, A. Do women receive compensating wages for risks of dying on the job? Social Science Quarterly, v. 72, n. 4, Dec. 1991, p. 727-737.

MIGUEL, A. S. S. R. Manual de Higiene e Segurança do Trabalho. Porto: Porto Editorial, 2007.

OLIVEIRA, P. R. Uma sistematização sobre a saúde do trabalhador: Do exótico ao esotérico. São Paulo: LTr, 2011.

PEREIRA, A. D. Tratado de segurança e saúde ocupacional. Volume 3: aspectos técnicos e jurídicos: NR-13 a NR-15. 2ª ed. São Paulo: Editora Saraiva, 2015. 
RODRIGUES, N. M. L. Conhecimento e Adesão às Medidas de Precaução Padrão dos Funcionários do Serviço de Higiene e Limpeza Hospitalar. Dissertação (Mestrado em Enfermagem). UNIFESP, São Paulo, 2001.

ROSEN, S. Hedonic prices and implicit markets. Journal of Political Economy, v. 82, jan 1974, p. 34-55. DOI: https://doi.org/10.1086/260169

SALIBA, T. M.; CORREA M. A. C.. Insalubridade e Periculosidade: Aspectos técnicos e práticos. São Paulo: LTr, 2012.

SALIBA, T. M.; PAGANO S. C. R. S. Legislação de Segurança, Acidente do Trabalho e saúde do trabalhador. São Paulo: LTr, 2010.

SALIM. C. A.; CARVALHO, L. F. Saúde e segurança no ambiente de trabalho: contextos e vertentes. Belo Horizonte: Fundacentro/Universidade Federal de São João Del Rei, 2002.

SMITH, A. A Riqueza das Nações: uma investigação sobre sua natureza e suas causas. $2^{a}$ ed.. São Paulo: Nova Cultural, 1985, v.1.

SMITH, R.; EHRENBERG, R. A Moderna Economia do Trabalho: Teoria e política pública. 5a ed.. São Paulo: Makron Books, 2000.

VISCUSI, W. K. Structuring an Effective Occupational Disease Policy: Victim Compensation and Risk Regulation. Yale Journal on Regulation, v. 2, n.1, 1984, p. 5381.

VISCUSI, W. K. The Impact of Occupacional Safety and Health Regulation, 1973-1983. The RAND Journal of Economics, v. 17, n. 4, 1986, p. 567-580. DOI: https://doi.org/10.2307/2555482

VISCUSI, W. K. The Value of Risks to Life and Health. Journal of Economic Literature, v. 31, 1993, p. 1912-1946.

VISCUSI, W. K.; ALDY, J. E.. The Value of a Statistical Life: ACritical Review of Market Estimates Throughout the World. Discussion Paper n. 392. Cambridge, MA: John M. Olin Center for Law, Economics, and Business, Harvard Law School, 2002. DOI: https://doi.org/10.3386/w9487 